\title{
Renal artery thrombosis and hypertension in a 13 year old girl with antiphospholipid syndrome
}

Pier Antonio Ostuni, Paolo Lazzarin, Vittorio Pengo, Amelia Ruffatti, Franco Schiavon, Pierfranca Gambari

\begin{abstract}
The case of a 13 year old girl with renal artery thrombosis and hypertension is described. A cerebrovascular accident and a probable occlusion of the superior mesenteric artery also occurred. Very high levels of 'lupus anticoagulant', anticardiolipin antibodies as well as false positive Venereal Disease Research Laboratory tests were repeatedly shown. Moreover, the patient fulfilled at least four classification criteria for systemic lupus erythematosus, but only a slight positivity for antinucleolar antibodies was present. The striking relation between antiphospholipid antibody levels and clinical events and the treatment of this complex syndrome are discussed.
\end{abstract}

Renovascular hypertension is one of the commonest forms of secondary hypertension. In the young the most usual pathological finding underlying the disease is fibromuscular dysplasia, whereas in the elderly atherosclerosis is the major cause. ${ }^{12}$ Less commonly reported is renal artery thrombosis, which usually occurs after lesions of the artery wall. ${ }^{1}$

In the past few years the relation between thrombosis and antiphospholipid antibodies has been increasingly reported. ${ }^{3-9}$ 'Lupus anticoagulant' and anticardiolipin antibodies have been found to be associated with both venous and arterial thrombosis, ${ }^{3-6} 10$ as well as with recurrent fetal loss, ${ }^{36}$ thrombocytopenia, ${ }^{7}$ false positive tests for syphilis, ${ }^{11}$ and Coombs' positivity. ${ }^{8}$

Since, to our knowledge, renal artery thrombosis has never been reported in association with antiphospholipid antibodies, in this paper we describe the case of a 13 year old girl with renal artery thrombosis and severe hypertension despite antihypertensive and steroid treatment the patient was admitted to our institute in May
At entry she presented with blood pressure $180 / 120 \mathrm{mmHg}$, nystagmus, stupor-like unconsciousness, and palmar erythema. A systolic diastolic periumbilical bruit was heard. Electrocardiogram and chest $x$ ray showed respectively left ventricular hypertrophy and a moderate enlargement of the cardiac shadow, and the echocardiogram showed a small pericardial effusion. An electroencephalogram showed severe and diffuse abnormalities, while cerebrospinal fluid and ophthalmoscopic examination as well as brain computed tomography were normal. Laboratory tests showed haemoglobin $94 \mathrm{~g} / \mathrm{l}$, erythrocyte sedimentation rate $78 \mathrm{~mm} / 1 \mathrm{st} \mathrm{h}$; blood urea $19.2 \mathrm{mmol} / \mathrm{l}$, serum creatinine $97 \mu \mathrm{mol} / 1$, prothrombin 0.71 , partial thromboplastin time $27 \mathrm{~s}$. Liver enzyme levels were raised: serum aspartate transaminase 45 $\mathrm{U} / \mathrm{l}$, serum alanine transaminase $82 \mathrm{U} / \mathrm{l}, \gamma$ glutamyl transferase $244 \mathrm{U} / \mathrm{l}$, alkaline phosphatase $901 \mathrm{U} / 1$. Microhaematuria and slight proteinuria (up to $0.9 \mathrm{~g} /$ day) were also found. Dilute Russell's viper venom time ${ }^{12}$ was $37 \cdot 4 \mathrm{~s}$ (control $23.7 \mathrm{~s}$ ). Very high levels of IgG anticardiolipin antibodies (1680 EU-quantitative enzyme linked immunosorbent assay (ELISA) technique) ${ }^{13}$ and a false positive VDRL test were also detected. Antinucleolar antibodies by immunofluorescence $(1 / 80)$ and immune complexes by Raji cell assay (IgG 1/32; IgM 1/8; IgA 1/4) were also found, while white blood cell count, platelets, $\mathrm{CH}_{50}, \mathrm{C} 3$, and $\mathrm{C} 4$ were all normal and Coombs' test was negative.

Plasma exchange was started in association with prednisone and antihypertensive drugs $(\beta$ blockers, prazosin, and enalapril).

Renal echotomography and angiophotoscintiscan showed a small and poorly perfused left kidney, while the right one presented cortical irregularities. Selective angiography showed a high grade stenosis of both renal arteries at their origin (fig 1). The left artery also had several filling defects extending into the intrarenal branches, which were interpreted as revascularised thrombosis (fig 2). Distal to the ostial stenosis, the right artery and its branches were normal. Riolan's arch was very prominent, probably owing to stenosis of the superior mesenteric artery (fig 1). Transluminal angioplasty by Grüntzig catheter was performed, obtaining an apparently appropriate dilatation of the right renal artery ostium, whereas the attempt made to insert the catheter into the left artery was unsuccessful. On the other hand, surgical revascularisation was discouraged owing to the diffuse involvement of the intraparenchymal vessels. After angiography and angioplasty the renal function deteriorated associated with lupus anticoagulant anticardiolipin antibodies, and false positive Venereal Disease Research Laboratory (VDRL) tests.

\section{Case report}

In April 1986 a 13 year old girl suddenly complained of severe cramping abdominal pain, accompanied by vomiting and a slight fever $\left(37 \cdot 5^{\circ} \mathrm{C}\right)$. After a few days gastrointestinal symptoms disappeared, while hypertension developed (blood pressure 180/140 $\mathrm{mmHg}$ ) together with fever $\left(39^{\circ} \mathrm{C}\right)$, convulsive seizures, oliguria, and haematuria.

Owing to the persistence of these symptoms 1986.

Rheumatology Padua, Italy

P Lazzarin

F Schiavon

Division of Cardiolog, Padua, Italy

V Pengo
} 
further. A subsequent renal scintiscan showed reduced blood flow also involving the right kidney. Treatment with oral anticoagulants (warfarin) was therefore added.

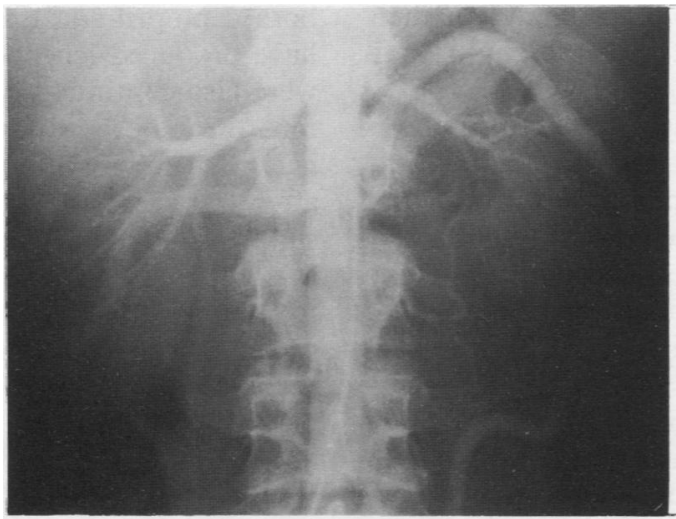

Figure 1: Renal angiography shows marked stenosis of both renal arteries at their origin. The left one presents several filling defects. Hypertrophic Riolan's arch is also evident.

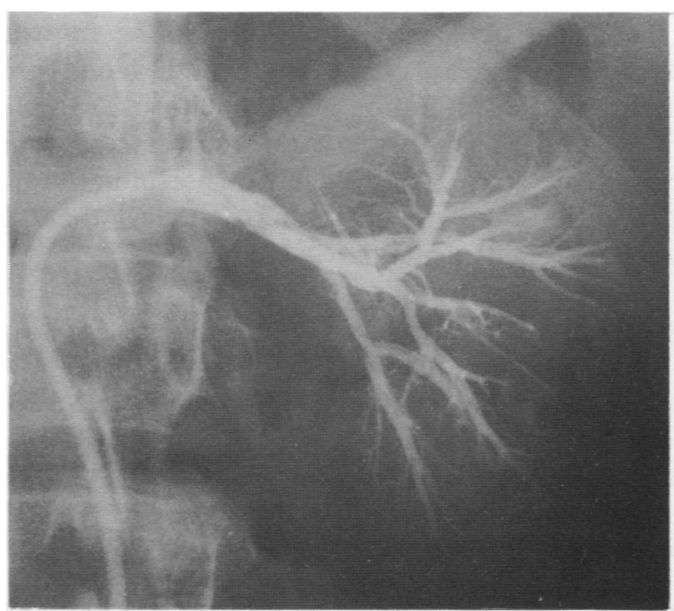

Figure 2: Selective angiography of the left renal artery: the magnification shows filling defects extending into the intrarenal branches.
One month later the patient developed neurological symptoms related to a cerebrovascular accident. Computed tomography showed an ischaemic area in the temporal lobe, suggestive of arterial thrombosis. Prednisone dose was increased and cyclophosphamide added. Subsequently, two episodes of leucopenia (white blood cells $<10^{9} / 1$ ) occurred. Firstly (December 1986), enalapril, then (May 1987) cyclophosphamide were withdrawn, and a normal white blood cell count was obtained rapidly in both cases.

In August 1987 she was promptly readmitted to our institute because of severe hypertension (blood pressure $240 / 140 \mathrm{mmHg}$ ) with a further impairment of renal function. Diffuse erythema and arthritis of the right elbow, wrist, metacarpophalangeal, and proximal interphalangeal joints were also present. Steroid dose and plasma exchange rate were increased, and treatment with furosemide, spironolactone, and azathioprine was added. Within two weeks a good remission was achieved.

In December 1987 the hypertension and renal function worsened again. Angiotensin converting enzyme inhibitors were restarted, but leucopenia (white blood cells $1.5 \times 10^{9} / 1$ ) and severe anaemia (haemoglobin $7 \mathrm{~g} / \mathrm{l}$ ) arose. Plasma exchange, azathioprine, and angiotensin converting enzyme inhibitors were withdrawn and the prednisone dose increased, resulting in a slow rise in haemoglobin concentration and white blood cell count.

The patient is now (January 1989) receiving prednisone ( $30 \mathrm{mg}$ daily), $\beta$ blocking agents, and anticoagulants, and her general condition remains satisfactory.

Figure 3 shows the variation in blood pressure, serum creatinine, lupus anticoagulant, anticardiolipin antibodies with time and the effect of the major treatments.

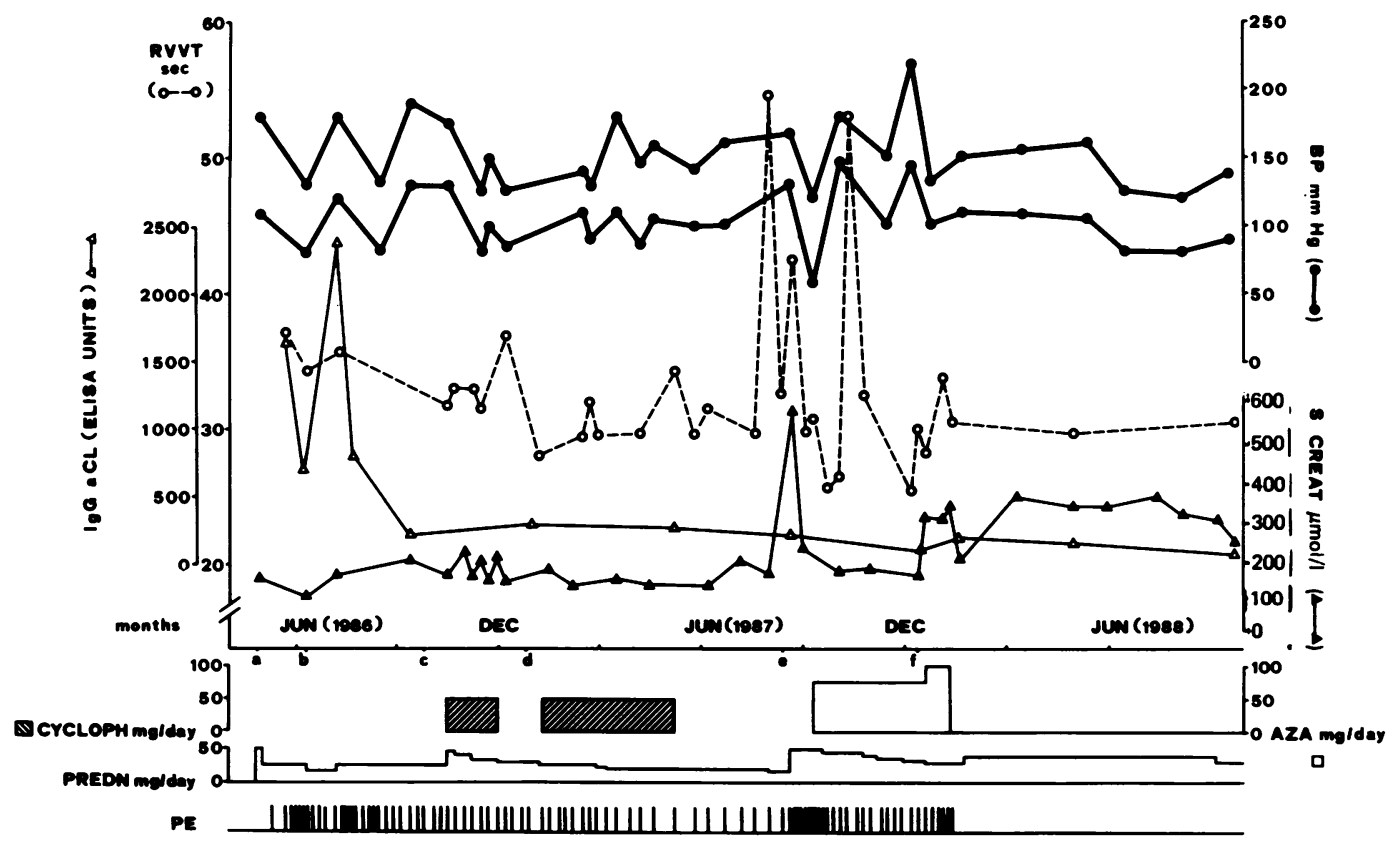

Figure 3: Variation of blood pressure, serum creatinine, 'lupus anticoagulant', and anticardiolipin antibodies cver two years. Major treatments are also indicated. $R V V T=R$ ussell's viper venom time; aCL=anticardiolipin; ELISA=enzyme linked immunosorbent assay; $B P=$ blood pressure; $S C R E A T=$ serum creatinine; $C Y C L O P H=$ cyclophosphamide; $P R E D N=$ prednisone; $P E=$ plasma exchange; $A Z A=$ azathioprine. 
Discussion

Recently, the term 'antiphospholipid syndrome' has been introduced to describe patients presenting venous and arterial thrombosis, recurrent abortions, and thrombocytopenia, associated with antiphospholipid antibodies, namely lupus anticoagulant and anticardiolipin antibodies. ${ }^{14}$

The various localisations of arterial thrombosis include cerebral, ${ }^{5-8} 1516$ retinal, ${ }^{17}$ coronary, ${ }^{18}$ mesenteric, ${ }^{10}{ }^{19}$ and peripheral vessels, ${ }^{16} 20$ but to the best of our knowledge renal artery thrombosis has never been reported. Only two cases of renal infarction have been described: one patient presented with asymptomatic segmental infarction ${ }^{21}$ and the other with haematuria and severe loin pain, which were attributed to infarct of the kidney. 22

Renal artery thrombosis is a rather rare condition occurring after abdominal trauma and, less commonly, after direct lesions of the renal artery. ${ }^{1}$ It has been also reported in polyarteritis nodosa ${ }^{23}$ and a single case of spontaneous thrombosis has also been described. ${ }^{24}$ In all these reports no data are available about the presence of antiphospholipid antibodies.

In our patient thrombosis of the renal artery was associated with hypertension and renal failure. The case also fulfilled sufficient American Rheumatism Association classification criteria for systemic lupus erythematosus ${ }^{25}$ namely, erythema, pericarditis, arthritis, and a false positive serological test for syphilis. Renal involvement, seizures, and leucopenia also appeared, but they might have been related to the concurrent hypertension or treatment, or both. Antinuclear antibodies with a nucleolar pattern were also present, and, although rare, they have been detected in systemic lupus erythematosus. ${ }^{26}$

Absence of a relation between antiphospholipid antibodies anti-double-stranded DNA and anti-extractable nuclear antigen antibodies has been reported in several studies. ${ }^{79} 27$ Similarly, there seems to be no relation between antiphospholipid antibodies and circulating immune complexes or decreased complement levels. ${ }^{27}$ Furthermore, multiple and severe arterial and venous thrombosis has been described in cases with clinically and serologically quiescent systemic lupus erythematosus. ${ }^{72} 28$ Our patient also developed multiple thrombosis, as shown by the cerebrovascular accident and the probable mesenteric artery occlusion demonstrated by the Riolan's arch hypertrophy and acute abdominal pain and vomiting.

Increasing evidence suggests that a cause and effect relation between antiphospholipid antibodies and thrombosis exists.$^{16}$

It has also been reported that the increase of antiphospholipid antibody levels has a predictive value for thrombosis. ${ }^{29}$ Our case confirms this view as increased levels of lupus anticoagulant were detected in several blood samples just before the disease relapsed.

Surgery, which is the definitive treatment for renovascular hypertension, ${ }^{2}$ was not attempted in our patient owing to the diffuse involvement of intrarenal arteries. Transluminal angioplasty was not successful and caused further renal damage. Thus the control of high blood pressure was achieved with rather high doses of several antihypertensive drugs. Angiotensin converting enzyme inhibitors were particularly useful, but both captopril and enalapril were suspected to have produced leucopenia. Oral anticoagulants were also continuously given to prevent recurrent thrombosis, as suggested by Asherson et $a l,{ }^{30}$ but cerebral injury supervened two months after warfarin was started. Steroids, immunosuppressive drugs (cyclophosphamide or azathioprine), and plasma exchange were used to reduce the production and increase the removal of antiphospholipid antibodies. ${ }^{28}$ This therapeutic regimen brought about a slow but definite reduction of lupus anticoagulant and anticardiolipin antibody levels.

Our report deals with the first case of renal artery thrombosis and hypertension occurring in a young patient with antiphospholipid syndrome and systemic lupus erythematosus, further extending the group of conditions which can determine renovascular hypertension and severe high blood pressure in systemic lupus erythematosus. Plasma exchange, immunosuppressive drugs, steroids, and anticoagulants may be useful in the antiphospholipid syndrome where no clear therapeutic guidelines seem yet available.

The authors gratefully acknowledge the technical assistance of Dr S Mariuz, Dr R Gusi, and Dr L Rossi.

1 Stimpel M, Groth H, Greminger P, Lüscher T F, Vetter H, Vetter $W$. The spectrum of renovascular hypertension. Cardiology 1985; 72 (suppl 1): 1-9.

2 Working group on renovascular hypertension. Detection evaluation and treatment of renovascular hypertension. Arch Intern Med 1987; 147: 820-9.

3 Hughes G R V. Thrombosis, abortion, cerebral disease and the lupus anticoagulant. $\mathrm{Br}$ Med $\mathcal{f}$ 1983; 287: 1088-9.

4 Anonymous. Anticardiolipin antibodies: a risk factor for venous and arterial thrombosis [Editorial]. Lancet 1985; i 912

5 Mueh J R, Herbst K D, Rapaport S I. Thrombosis in patients with the lupus anticoagulant. Ann Intern Med 1988; 92 156-8.

6 Carreras L O, Defreyn G, Machin S J, et al. Arterial thrombosis, intrauterine death and the lupus anticoagulant detection of immunoglobulin interfering with prostacyclin formation. Lancet 1981; i: 244-6.

7 Boey M L. Colaco G B, Gharavi A E, Elkon K B, Loizou S, Hughes G R V. Thrombosis is SLE: striking association with the presence of circulating "lupus anticoagulant". $\mathrm{Br}$ with the presence of circulating

8 Elias M, Eldor A. Thromboembolism in patients with the "lupus like" circulating anticoagulant. Arch Intern Med 1984; 144: 510-5.

9 Harris E N, Gharavi A E, Boey M L, et al. Anticardiolipin antibodies: detection by radioimmunoassay and association with thrombosis in systemic lupus erythematosus. Lance 1983; ii: $1211-4$.

10 Asherson R A, Mackworth-Young C G, Harris E N, Gharavi $A$, Hughes $G R$ V. Multiple venous and arterial thrombosis associated with the lupus anticoagulant and antibodies to cardiolipin in the absence of SLE. Rheumatol Int 1985; 5: 91-3.

11 Johansson E A, Lassus A. The occurrence of circulating antibodies in patients with syphilitic and biologically false positive antilipoidal antibodies. Ann Clin Res 1974; 6: positive $105-8$.

12 Thiagarajan P, Pengo V, Shapiro S S. The use of the dilute Russell viper venom time for the diagnosis of lupus anticoagulants. Blood 1986; 68: 869-94.

13 Gharavi A E, Harris E N, Asherson R A, Hughes G R V. Anticardiolipin antibodies: isotype distribution and phospholipid specificity. Ann Rheum Dis 1987; 46: 1-6.

14 Hughes G R V, Harris E N, Gharavi A E. The anticardiolipin syndrome. I R Reumatol 1986; 13: 486-9.

15 Hart R G, Miller V T, Coull B M, Bril V. Cerebral infarction associated with lupus anticoagulant-preliminary report. Stroke 1984; 15: 114-8.

16 Harris E N, Gharavi A E, Asherson R A, Boey M L, Hughes G R V. Cerebral infarction in systemic lupus: association with anticardiolipin antibodies. Clin Exp Rheumatol 1984 1: 47-51. 
17 Hall S, Buettner H, Harvinder L S. Occlusive retinal vascular disease in systemic lupus erythematosus. $\mathcal{F}$ Rheumatol 1984; 11: $846-50$.

18 Hamsten A, Norberg R, Björkholm M, De Faire U, Holm G. Antibodies to cardiolipin in young survivors of myocardial infarction: an association with recurrent cardiovascular events. Lancet 1986; i: $113-6$

19 Asherson R A, Morgan S H, Harris E N, Gharavi A E, Krausz T, Hughes G R V. Arterial occlusion causing large bowel infarction: a reflection of clotting diathesis in SLE. Clin Rheumatol 1986; 1: $102-6$.

20 Asherson R A, Harris E N, Gharavi A E, et al. Arterial occlusions associated with antibodies to cardiolipin occlusions associated with antibodies to cardi

21 Arnold M H, Schrieber L. Splenic and renal infarction in systemic lupus erythematosus: association with anti-cardiolipin antibodies. Clin Rheumatol 1988; 3: 406-10.

22 Asherson R A, Derksen R H W M, Harris E N, et al. Chorea in systemic lupus erythematosus and "lupus-like" disease: association with antiphospholipid antibodies. Semin Arthritis Rhewm 1987; 16: 253-9.

23 Templeton P A, Osher-Pais S. Renal artery occlusion in PAN. Radiology 1985; 156: 308.

24 Cobos J M, Hisano K, Shida T, Tsubota N, Okada M, Nakamura K. Renovascular hypertension due to spon- taneous thrombosis formation-a successful case treated by saphenous vein bypass grafting. Kobe f Med Sci 1981; 27: 201-6.

25 Tan E M, Cohen A S, Fries J F, et al. The 1982 revised criteria for the classification of systemic lupus erythematosus Arthritis Rheum 1982; 25: 1271-7.

26 Meyer O, Bourgeois P, Zakraoui L, et al. Maladie lupique avec anticorps antinucléaires de type nucléolaire. Rev Rhum Mal Osteoartic 1988; 55: 1-6.

27 Derkesen R H W M, Bouma B N, Kater L. The prevalence and clinical associations of the lupus anticoagulant in systemic lupus erythematosus. Scand $\mathcal{f}$ R heumatol 1987; 16: systemic

28 Sturfelt G, Nived O, Norberg R, Thorstensson R, Krook K. Anticardiolipin antibodies in patients with systemic lupus erythematosus. Arthritis Rheum 1987; 30: 382-8.

29 Harris E N, Chan J K H, Asherson R A, Gharavi A E, Hughes G R V. IgG anticardiolipin antibody (ACAG) possible predictor for thrombosis, thrombocytopenia and recurrent abortion [Abstract]. Arthritis Rheum 1985; 28 (suppl): S38.

30 Asherson R A, Chan J K H, Harris E N, Gharavi A E, Hughes G R V. Anticardiolipin antibody, recurrent thrombosis and warfarin withdrawal. Ann Rheum Dis 1985; 44: 823-5. 